\title{
A Systems Approach to Examining PhD Students' Well-Being: An Australian Case
}

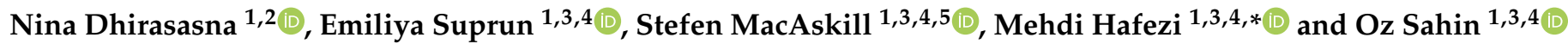 \\ 1 Griffith Systems Modelling Group, Griffith University, Gold Coast, QLD 4222, Australia; \\ nina.dhirasasna@griffithuni.edu.au (N.D.); e.suprun@griffith.edu.au (E.S.); \\ Stefen.MacAskill@griffithuni.edu.au (S.M.); o.sahin@griffith.edu.au (O.S.) \\ 2 Griffith Institute for Tourism, Gold Coast, QLD 4222, Australia \\ 3 School of Engineering and Built Environment, Griffith University, Gold Coast, QLD 4222, Australia \\ 4 Cities Research Institute, Griffith University, Nathan, QLD 4111, Australia \\ 5 Griffith Business School, Griffith University, Gold Coast, QLD 4222, Australia \\ * Correspondence: mehdi.hafezi@griffithuni.edu.au
}

Citation: Dhirasasna, N.; Suprun, E.; MacAskill, S.; Hafezi, M.; Sahin, O. A Systems Approach to Examining PhD Students' Well-Being: An Australian Case. Systems 2021, 9, 17. https:// doi.org/10.3390/systems 9010017

Academic Editor: Andrea Pitasi

Received: 11 December 2020

Accepted: 18 February 2021

Published: 23 February 2021

Publisher's Note: MDPI stays neutral with regard to jurisdictional claims in published maps and institutional affiliations.

Copyright: (c) 2021 by the authors. Licensee MDPI, Basel, Switzerland. This article is an open access article distributed under the terms and conditions of the Creative Commons Attribution (CC BY) license (https:/ / creativecommons.org/licenses/by/ $4.0 /)$.

\begin{abstract}
Previous research regarding PhD students' well-being (PhD-WB) has lacked a comprehensive and systemic analysis. This research engages with a systems approach to examine the multiple variables, including feedback mechanisms, which influence PhD-WB over time. The model was developed using a structural analysis method (Cross-impact analysis MICMAC) that informed a causal loop diagram (CLD). The aim was to understand what promotes (drivers) and inhibits (barriers) PhD students' well-being. The results show that $\mathrm{PhD}$ students' well-being reflects an interplay between university, financial support, students' mental and physical health, and family/friends. However, the analysis shows that the role of the drivers is dynamic, and they can become barriers in certain circumstances. This insight validates the application of systems thinking to illustrate the complexity of PhD students' well-being.
\end{abstract}

Keywords: PhD students; well-being; systems approach; system archetypes; causal loop diagram (CLD)

\section{Introduction}

PhD students are often associated with poor well-being [1]. Almost half of the PhD candidates across all disciplines have reported intention to interrupt their studies as a result [2]. The mental health of PhD students, such as stress and anxiety, are the common reasons for PhD student burnout [3]. These, alongside other factors, have resulted in student attrition rates as high as 50\% [4]. Understanding the possible systematic issues that exacerbate PhD students' well-being (PhD-WB) could assist universities in minimising the cost associated with dropouts, such as loss of facility allocations, scholarship, and supervisory time, in addition to the psychological costs be experienced by PhD students [4]. Understanding drivers and barriers to $\mathrm{PhD}-\mathrm{WB}$ is of paramount importance, specifically to deliver high-quality research outcomes for universities. The World Health Organization's (WHO) holistic definition of well-being as "the state of complete physical, mental and social well-being and not merely the absence of disease or infirmity" [5] was adopted in this research.

PhD students coping strategies to maintain their well-being form an influential role in their post candidature life and transition to professional careers [6]. Academic staff often experience poor well-being [1,7], which may indicate that strategies to maintain their well-being developed during their early years of the PhD candidature were insufficient. Providing PhD students with the right tools to remain healthy during their candidature could ensure a seamless transition to cope with the rigour of professional academic roles, and subsequently, improve the sustainability of higher education system. 
Previous research has conceptualised PhD student's well-being from different perspectives. Emotional exhaustion, for example, causes $\mathrm{PhD}$ students to leave academia after completing their degree [8]. Loneliness and insecurity can adversely affect the phycological aspects of PhD-WB [9]. The academic communities also influence PhD-WB; opportunities for learning, and the perceived meaningfulness of their research [10]. Further, PhD-WB is influenced internally by conflicts arising from self-reflection [11], time for oneself [12], and role conflicts (i.e., in life, marriage and work) [13].

These different perspectives on PhD-WB highlight that the well-being of PhD students comprises several interactive components whose relationships are inherently non-linear. Such interactions between factors indicate a systematic issue leading to high attribution rate and poor well-being among $\mathrm{PhD}$ students. However, previous research of $\mathrm{PhD}-\mathrm{WB}$ is limited and was primarily concentrated on isolated determinants of well-being rather than taking a multidimensional perspective and considering the dynamically complex systems shaping well-being [14,15]. This research asserts that an adequate and in-depth understanding of the PhD-WB necessitates understanding the relationships between system behaviour and system structure which influence PhD-WB.

The overarching goal of this research is to explore the underlying factors that could cause severe mental health problems for PhD students during their candidature. The systems approach provides a suitable platform to explore well-being in a higher education context because it incorporates feedback mechanisms [16,17]. Subsequently, this research presents the system elements of PhD-WB from the viewpoint of a university in Queensland, Australia, which is based on non-specialist interpretations of well-being from $\mathrm{PhD}$ students, family members and supervisors. The three objectives are (1) identifying variables, their roles, and relationships, directly related to $\mathrm{PhD}-\mathrm{WB}$ in the case study; (2) illustrating the interaction between variables with a causal loop diagram (CLD) to explain the nature of $\mathrm{PhD}-\mathrm{WB}$; and (3) using a CLD to understand the system dynamics and the role of drivers as potential enablers and barriers shaping $\mathrm{PhD}-\mathrm{WB}$.

The key points from the literature on PhD-WB and information regarding the case study are discussed. Subsequently, $\mathrm{PhD}-\mathrm{WB}$ is analysed as experienced by $\mathrm{PhD}$ students, their supervisors, families and friends. To conclude, salient recommendations to improve PhD-WB are provided to identify intervention strategies with the capacity of improving $\mathrm{PhD}-\mathrm{WB}$. The systems approach is employed in this research, and therefore, is presented as an apt approach for universities to understand the purposeful as well as unintended consequences of their policies.

\section{Literature Review}

\subsection{PhD-WB Synopsis}

$\mathrm{A} \mathrm{PhD}$, unlike other higher education degrees, is a pure research degree for approximately three to four years. Traditionally, PhD graduates are prepared for an academic position and thus are encouraged to engage in research and teaching assistantship roles in addition to their PhD research. In the current stage, however, as few as 5\% of $\mathrm{PhD}$ graduates secure a permanent academic position. Many students transition into industry roles unrelated to academia which often do not use the skills and knowledge they have developed during their candidature [18]. In this context, the experiences of PhD students are often characterised by stress, pressure and uncertainty [19].

Growing research in PhD-WB has identified several factors negatively impacting well-being. For example, viewing a $\mathrm{PhD}$ education as a product rather than a process [20]; measuring PhD students' performance based on the number of articles in the high-ranking journals [21]; paper deadlines, high workloads and expected active participation in the scholarly environment [21]; limited support from the university and supervisors [22]; conflicting commitments other than their $\mathrm{PhD}$, limited finances, lack of future job securities [13]; and existing illnesses and physical conditions [13,23]. However, the previous studies on PhD-WB were criticised for concentrating on isolated determinants of well-being rather than taking a multidimensional perspective. It is important to consider a diverse 
range of influential factors which interact simultaneously, which together create a more holistic view of well-being $[15,24]$.

Suggestions and practical implications were made in previous research to improve the well-being of $\mathrm{PhD}$ students. For example, teaching PhD students to think positively [20], fostering student communities [10], organising health labs, fitness classes, and seminars on time management [11], engaging supervisors [25], and training supervisors how to provide constructive feedback [8]. However, previous research has been criticised for failing to address how doctoral education could be improved [14].

\subsection{Conceptual Framework}

PhD-WB can be conceptualised by PhD students' emotional states. Quite often they experience negative emotional states, such as stress and exhaustion, during their candidature $[25,26]$. Experiencing positive well-being may promote PhD project engagement and, vice versa, experiencing poor well-being can be a cause for withdrawal and disengagement. Fredrickson [16]'s 'Broaden-and-Build Theory of Emotions' was acknowledged suitable to explain PhD students' emotional experiences [25]. Fredrickson [16] suggests that negative emotions such as distress could narrow one's attention and capacity to focus on multiple tasks. In response, one is forced only to focus on performing well in certain tasks. This statement implies that experiencing well-being might influence one's ability to attain the desired learning outcomes. Fredrickson's theory has been used to explain how the well-being of students is linked with a student's perception of the meaningfulness of their PhD study [25]. Further linkages include the secondary school student's satisfaction with life and their academic performance [27], and university lecturers' confidence in their teaching with coping skills when dealing with student feedback [28].

In the PhD student context, however, the PhD project is beyond students' emotions as described by Fredrickson [16]. PhD project requires supervisions and university facilities such as laboratories and libraries. Interactions with $\mathrm{PhD}$ peers and supports from family can contribute to $\mathrm{PhD}-\mathrm{WB}$ [23]. The debate concludes that $\mathrm{PhD}-\mathrm{WB}$ is dynamic in nature because of the multidimensional forces, including universities, supervisory teams and finances $[15,24]$. Thus, to understand the complex problem of PhD-WB and examine the phenomenon from multiple perspectives, this research subscribes to the notion of theoretical pluralism [29], and augments Fredrickson's initial theory with two other relevant theories, namely Demerouti et al.'s [30] job demands-resources model and Liden and Maslyn's [31] leader-member exchange theory.

First, a comprehensive theoretical framework needs to accommodate the fact that $\mathrm{PhD}$ students are more likely to experience positive well-being if they receive social support from their PhD supervisors, university and peers during their candidature [23]. The importance of resource and support is addressed in Demerouti et al.'s job demands-resources model (JD-R) [30]. Demerouti et al. [30] assert that job demands, and resources can enhance work engagement, and subsequently, employee well-being. Job demands refer to physical, psychological, social and organisational aspects of the job that requires an effort, such as time to complete $\mathrm{PhD}$, and emotional demand to complete $\mathrm{PhD}$. Job resource is defined as the physical, psychological, social and organisational aspects of the job that simulate personal growth, such as PhD supervisor support and feedback, other PhD students, and university facilities. In PhD-WB literature, JD-R explains PhD students' engagement and their perceived supervisor's and university's support, $\mathrm{PhD}$ satisfaction, and their stress level [22], university graduates and their development of employability [32], the academic work environment and faculty well-being [33].

Second, the quality of PhD supervision can influence PhD-WB as the supervisors play the role of guidance and support [34]. Quality of mentorship was found to promote a positive and successful academic experience for the student [35,36]. Liden and Maslyn's leader-member exchange theory focuses on this supervisor-student relationship [31]. Liden and Maslyn [31] contend that the quality of such relationships depends on the contribution that both sides put forward to achieve the goal, how both parties support each other, 
interpersonal attraction other than work values, and professional respect. Leader-member exchange theory explains the quality of teacher-student relationship its impact on student achievement in the career and technical education setting [37] and university setting [38].

This research responds to Moberg [24] and Schmidt and Hansson [15] call for a broader examination of PhD student well-being. The integration of Fredrickson [16]'s, Demerouti, Bakker, Nachreiner and Schaufeli [30]'s, and Liden and Maslyn [31]'s theories has not been undertaken in the PhD-WB context to date, possibly due to the absence of modelling techniques that can cope with complex systems analyses. Drawing on a systems approach that can capture the interrelatedness among system elements and how they can impact themselves [39], this research aims to connect Fredrickson [16]'s, Demerouti, Bakker, Nachreiner and Schaufeli [30]'s, and Liden and Maslyn [31]'s theories and forms a basis of system interaction for PhD student well-being in Queensland, Australia (see Figure 1).

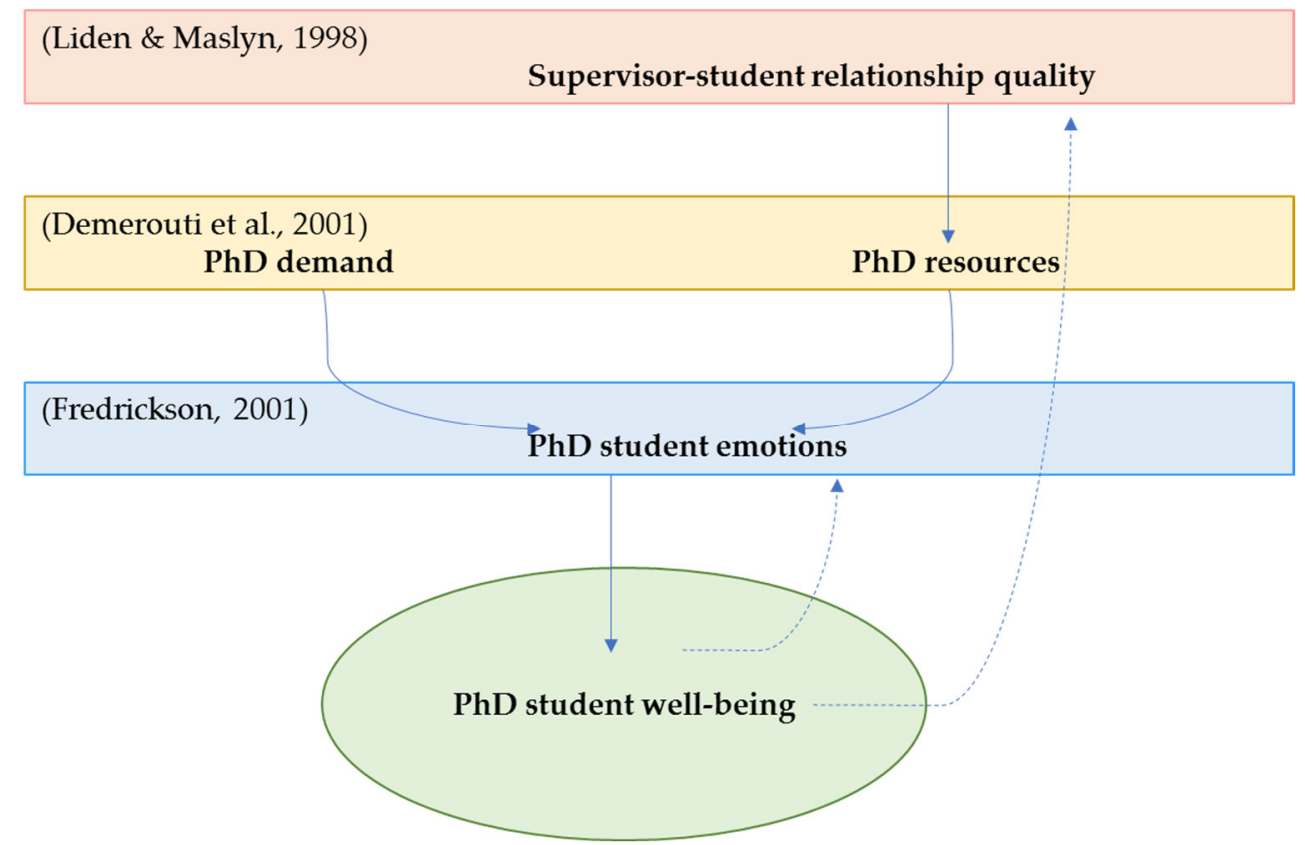

Figure 1. The conceptual framework of PhD student well-being in Queensland, Australia, integrating the theories of Fredrickson [16], Demerouti, Bakker, Nachreiner and Schaufeli [30], and Liden and Maslyn [31].

\subsection{Case Study: Griffith University, Australia}

The Australian higher education sector is a substantial part of the economy [40]. Among total enrolments in 2018, 63\% consisted of domestic and 37\% of international students [40]. In 2016, over 1.4 million students were enrolled in this sector, of which approximately 400,000 are working towards Master's and Doctoral degrees [40]. In SouthEast Queensland, over 43,000 students are enrolled within postgraduate degrees [40]. Griffith University (GU) is one of the South-East Queensland largest universities and, thus, is deemed suitable for this research.

PhD students in Australia show to be aged between 25-34 [40]. The maximum length of PhD candidature in Australia is four years full-time, and up to the maximum of eight years part-time, which is available only to domestic students without the need to pay tuition fee. PhD students are overseen by two or more supervisors. GU provides PhD students with research amenities and services depending on the students' specific needs such as personal desks, computers, access to printing facilities, personalised email, data and information services, lab access and specialist equipment. Workshops, group seminars, and lectures from distinguished visitors are held regularly and provide opportunities for social interaction with other research students and academic staff [41]. University-led social gathering events are also available for postgraduate students throughout the year. 
Domestic PhD students are exempt from tuition fees under the Commonwealth Research Training Program and are often in receipt of living allowance scholarships [42]. In some cases, industry partnerships offer scholarships directed to specific fields of research. GU offers financial assistance up to AU\$8,000 including conference travel grants, research equipment and publication funds to eligible candidates, over the course of their candidature.

Despite GU's support for students, some challenges threaten PhD-WB. GU requires a minimum of one journal publication for a $\mathrm{PhD}$ student to graduate, while supervisors commonly require three peer-reviewed publications, adding pressure to students. In addition, financial and time pressures also persistent in PhD students. International PhD students who are in receipt of a scholarship, are under pressure to graduate prior to the scholarship expiry (typically three years) in order to avoid a significant tuition fee liability. Students who are ineligible for scholarship, and domestic students who have exceeded their candidature duration are liable for tuition fees up to AU\$33,000 per year, adding to the financial pressure. Students relying on a living allowance scholarship may find their stipend enables only a basic and single lifestyle. In 2017, the living allowance scholarship was AU\$27,082 per annum and was slightly higher than the Australian AU\$21,533 poverty line for a single adult [43]. In contrast, the average Australian full-time working wage is AU\$85,956 per annum [44]. Given that Australian living costs are amongst the highest in the world [45], PhD students may have to compromise in their living arrangements or delay medical procedures, which further decrease their well-being.

Some, particularly, but not limited to, international PhD students, may experience the absence of social support structures, which may pose a source of additional stress. Resultant stressors related to social support networks may present themselves through a lack of an established social network, language and cultural barriers. Regional domestic students may leave their family and friend circle to pursue higher education. Students completing their work remotely, by geographical circumstance or practical requirements to complete their research away from universities, may have limited support from other PhD students.

\section{Research Methods}

3.1. Systems Approach

The systems thinking approach explores the holistic and non-linear connections between factors. Changes in one factor can change the entire system through feedback loops and time delays [46]. Feedback loops are interrelated variables that can amplify the system (positive feedback) or inhibit the system (negative feedback) [39].

This research involved stakeholders in developing the model in face-to-face semistructured interviews, quantitative structural analysis method (Cross-impact analysis MICMAC), and a focus group discussion. The research design included multiple steps. Each step addresses a research objective (Figure 2). First, MICMAC was used instead of the traditional qualitative approach to identify exogenous (beyond the system) and endogenous (within the system) variables and served as a quantifiable model boundary. Then, the literature and researchers' prior knowledge about the relationships between the identified variables were used to develop the primary. This primary CLD was presented in the stakeholder interviews (results in the working CLD) and in a focus group discussion (results in the final CLD). The final CLD was interpreted by using system archetypes to understand the patterns of PhD-WB and to identify interventions to improve PhD-WB. This multiple-step research design follows the methodological pluralism for the systems modelling approach, which stated that no single method, whether it is a systems approach or otherwise, could address every question $[47,48]$. 


\begin{tabular}{|c|c|c|c|}
\hline Research Objectives & Systems Approach & Activities & Results \\
\hline \multirow{4}{*}{$\begin{array}{l}\text { 1. Identifying variables, their roles, } \\
\text { and relationships, directly related to } \\
\text { PhD-WB in the case study. }\end{array}$} & \multirow[t]{3}{*}{$\begin{array}{l}\text { Structural analysis method (Cross- } \\
\text { impact analysis MICMAC) }\end{array}$} & Literature review & 44 variables \\
\hline & & Expert refinement & 14 variables \\
\hline & & $\begin{array}{l}\text { Stakeholder identify degree of } \\
\text { influence/dependence }\end{array}$ & 14 variables and their roles \\
\hline & $\begin{array}{l}\text { Expert-stakeholder identification } \\
\text { method }\end{array}$ & Experts identify stakeholders & $\begin{array}{l}3 \text { groups of high propriety } \\
\text { stakeholders }\end{array}$ \\
\hline \multirow[t]{3}{*}{$\begin{array}{l}\text { 2. Illustrating the interaction between } \\
\text { variables to explain the nature of PhD- } \\
\text { WB }\end{array}$} & \multirow[t]{3}{*}{ Causal loop diagram (CLD) } & $\begin{array}{l}14 \text { variables based on literature review } \\
\text { and researchers' knowledge about } \\
\text { their relationships }\end{array}$ & CLD1 \\
\hline & & 3 stakeholder reviews (interviews) & CLD2 \\
\hline & & 11 stakeholder reviews (focus group) & Final CLD \\
\hline $\begin{array}{l}\text { 3. Understanding and interpreting the } \\
\text { CID and the role of drivers as } \\
\text { potential enablers and barriers } \\
\text { shaping PhD-WB. }\end{array}$ & System archetype & $\begin{array}{l}\text { Identify system archetype within the } \\
\text { final CI.D }\end{array}$ & $\begin{array}{l}2 \text { archetypes: Limits to Success, Fixes } \\
\text { that Fail. }\end{array}$ \\
\hline $\begin{array}{l}\text { Suggesting improvements to } \\
\text { university policy and culture that are } \\
\text { more inline with PhD-WB promotion }\end{array}$ & System archetype & $\begin{array}{l}\text { Identify the leverage points of each } \\
\text { identified archetype, and offer } \\
\text { possible strategy }\end{array}$ & $\begin{array}{l}\mathrm{PhD} \text { thesis deadline and shift in } \\
\text { emphasising on publication to skill } \\
\text { building. }\end{array}$ \\
\hline
\end{tabular}

Figure 2. Overview of methodological steps undertaken in this research.

\subsection{MICMAC-A Structural Analysis Method}

The quantitative structural analysis (MICMAC) is a scenario planning method, which classifies and quantifies variables based on their levels of influence/dependence [49]. MICMAC is recommended when quantitative data is lacking or when collection is otherwise infeasible. Previous research using the systems thinking approach has applied MICMAC to identify variables and pre-conceptualise the model complexity [50-52]. MICMAC addresses the first objective of this research to identifying variables, their roles, and relationships directly related to $\mathrm{PhD}-\mathrm{WB}$ in the case study.

MICMAC has three processes, starting with creating a variable inventory [49]. In this study, following the literature review, 44 variables related to physical activity, $\mathrm{PhD}$ candidature, mental health, and finance were identified. According to Müller et al. [53], experts can represent stakeholder perspectives and are appropriate for a validating task. Subsequently, this list of 44 variables was sent to a psychology expert, two PhD supervisors, and a higher education expert for the final revision. Based on the experts' feedback, the essential variables were identified, and 11 variables not critical to $\mathrm{PhD}-\mathrm{WB}$ were excluded; some overlapping variables were grouped together as nine single variables, while one new variable was added to the list. As a result, a total of 14 were retained based on their importance (see Appendix A). These 14 variables act as a starting and not the final variable inventory. Variables \#4, \#9, and \#10 correspond to Fredricson's focus on emotions and wellbeing [16]; variables \#5, \#8, and \#13 corresponded to Demerouti et al.'s notion on available resources [30]; and variables \#2 corresponded to Liden \& Maslyn's concern with supervisor and student relationship [31]. Variable including \#1, \#3, \#6, \#7, \#11, \#12 were not reflected in the theoretical framework but related to PhD students' in the Australian context.

The second MICMAC process involved asking stakeholders to quantify the degree of influence and dependence one variable had on the others [49]. Researchers and system modellers have applied different methods for the stakeholders' identification step in the systems approach, and specifically MICMAC [54,55]. This research applied an expert stakeholder identification procedure following the approach suggested by Chevalier and Buckles [56]. This approach allows modellers to identify and sort stakeholders on a 
'rainbow diagram' by whether stakeholders (1) 'affect', (2) 'are affected by', or (3) 'affect and are affected by' the phenomenon; by their role degrees of 'most', 'moderate' or 'least' [56]. Through the stakeholder identification process held by the authors, nine stakeholder groups including PhD supervisors, family members, friends, PhD colleagues, housemates, landlords, doctors and counsellors, and university staff were distinguished (Figure 3). Stakeholders were ranked based on their levels of influences on PhD-WB. For practical purposes, this research limits the number of stakeholders to those who had the most influence on PhD students at GU. The process results in three high priority stakeholder groups, including PhD supervisors, PhD students' family members, and PhD students.

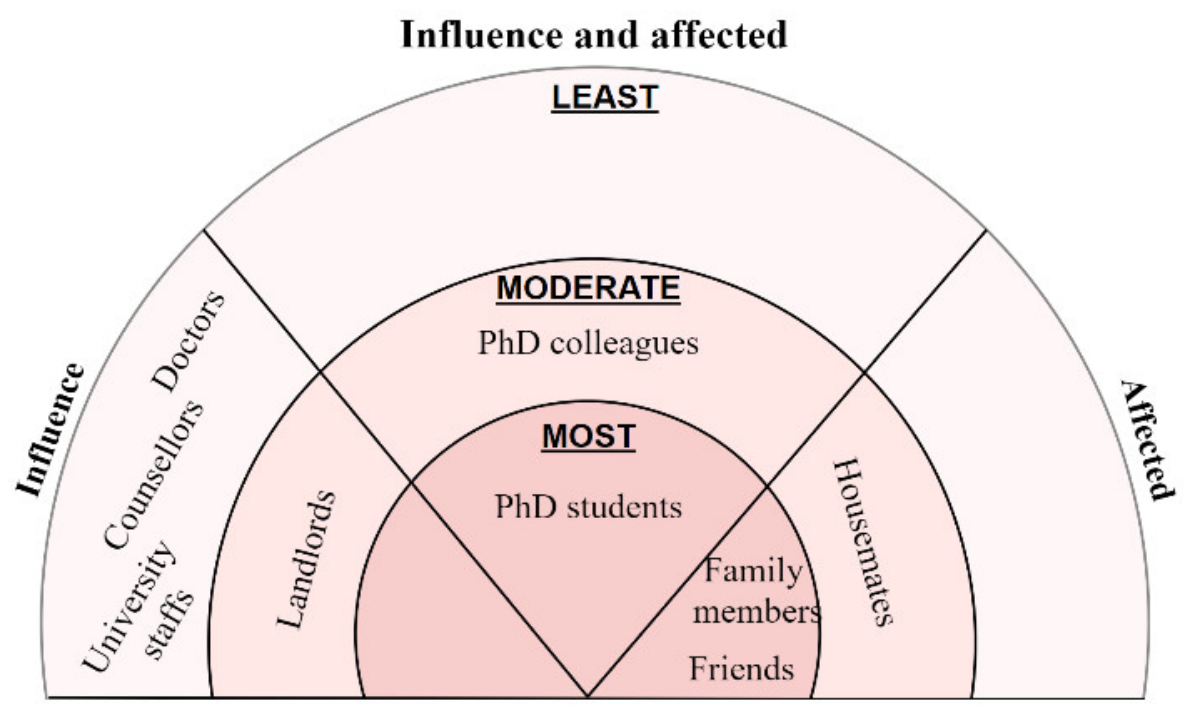

Figure 3. The identified stakeholders influencing, both influencing and affected, and affected by $\mathrm{PhD}$ students' well-being. Griffith University, Australia.

Each stakeholder received the information package containing a project introduction, the matrix and a glossary of variables. The stakeholders were asked, "If variable $i$ changed, what would be its direct impact on variable $j$ ?", with possible results of no influence (0); weak influence (1); medium influence (2); and strong influence (3). Stakeholders were given two weeks to fill out the matrix to the best of their ability. Space was given if stakeholders wished to insert their own variables, although no one had taken this option. In total, this matrix raised a total number of 196 questions $(14 \times 4$ variables), some of which would have been evaded if a systematic exploration had not taken place [49].

The final MICMAC process was to categorise variables based on stakeholders' responses. MICMAC categorises variables into nine groups based on their role and characteristics within the system (see Table 1), which are more detailed than the traditional systems thinking approach's endogenous/exogenous categories [54]. In this research, the responses were aggregated using a geometric mean, and analysed them in the MICMAC software version 6.1.2 [57]. MICMAC produces an influence and dependence graph, which displays variables at various locations depending on their roles. Researchers identified variable roles by comparing the variable positions with the guideline found in Arcade et al. [49]. In this research, no disconnected variables were identified, indicating that all 14 variables were endogenous and related to PhD-WB. Variables identified from the MICMAC process were used as a starting variable inventory in the next CLD process and were not a finite list. 
Table 1. Nine types of variables based on the influence $x$ dependence chart as per the structural analysis method (Crossimpact analysis MICMAC) (Adopted from Arcade et al. [49]).

\begin{tabular}{|c|c|}
\hline Variable Category & Definition \\
\hline Determinant variable & Very influent with little dependence, and can act on the system \\
\hline Environment variable & Conditions the system and cannot be controlled. \\
\hline Relay variable & Very influent and very dependent. They have a consequence on other variables if they are impacted. \\
\hline Stake variable & The 'potential breakpoint of the system' or have a strong influence on the system \\
\hline Target variable & More dependent than influent but can influence the system if it is conducted upon a desirable way. \\
\hline Dependent variable & $\begin{array}{c}\text { Little influent and very dependent, sensitive to changes of determinant and relay variables, and is the } \\
\text { result of the system. }\end{array}$ \\
\hline Autonomous variable & Little influent and little dependent. \\
\hline Disconnected variable & Its origin is excluded from the studied system. \\
\hline Secondary lever & More influent than dependent and is the possible secondary actor of the system. \\
\hline
\end{tabular}

\subsection{Causal Loop Diagram (CLD)}

Addressing the second objective, the PhD-WB system was mapped using a CLD in the Vensim software version DSSx32 6.3E (Ventana Systems, Inc.). A CLD consists of variable names connected with arrows indicating their causal relationships. Arrows marked with ' + ' indicate a causal relationship changing in the same direction (i.e., if A increases, B also increases); or '-' for opposite direction (i.e., if A increases, B decreases, and vice versa); and with 'II' for a delayed impact. A feedback loop is formed when one traces along with the arrows and ends with the starting variable. A feedback loop can reinforce the exponential growth or decline over time (denoted with ' $\mathrm{R}$ '), or balance or stabilise the system behaviour (denoted with ' $\mathrm{B}$ '). These $\mathrm{R}$ and $\mathrm{B}$ denotations appear in a $\circlearrowleft$ for loops reading anti-clockwise, and in $\circlearrowright$ for loops reading clockwise [39].

The CLD in this research was developed and refined through three stages. First, the primary CLD was drawn based on the literature review and the researchers' prior knowledge about PhD-WB. Then, the primary CLD was based on the interview results with a PhD supervisor, a PhD student, and a PhD student's spouse. During these individual face-to-face interviews, the researchers explained the primary CLD and the feedback loops using VENSIM software. The interviewees could edit the variable names, definitions and their relationships directly into the diagram. Changes made from one interview were introduced to the next. Relationships between variables that interviewees disagreed upon were discussed in the third stage. This process resulted in the working CLD. There is no required number of interviewees for a systems approach because the stakeholder involvement is to illuminate their perspectives [58].

Third, the working CLD was reviewed by stakeholders in a focus group meeting. One week prior to the focus group meeting, the working CLD and variable glossary were sent to stakeholders. Eight PhD students, two PhD supervisors and one PhD student's family member (i.e., spouse) agreed to attend a focus group meeting, during which they could add/delete any variables or arrows and identify potential feedback loops.

Finally, the working CLD was again discussed with PhD students, PhD supervisors and university staff attending two presentations about Griffith university workplace mental well-being. This process resulted in the final CLD (reporting in this paper). Note that a lack of family representatives, particularly parents in the focus group, could result from their work/family obligations. In addition, selecting university as the focus group venue might be inconvenient for family members. Nonetheless, the family members were involved in the MICMAC process and private interviews prior to a focus group.

\subsection{System Archetypes and Leverage Points}

The final CLD was used to address the third research objective to analyse the system and identify system archetypes. Although CLDs could be visually complex, identifying behaviours of a CLD using system archetypes can illuminate underlying problems. System archetypes are the common system behaviours [59], such as fixes that fail, drifting goals, 
success to the successful, limits to success, and tragedy of the commons (See [59] for archetype list). Each archetype comprises of reinforcing and balancing feedback loop and has a leverage point which can change the system behaviour [60]. For example, the drifting goals archetype is when poor performance is tolerated and leads to lower expectations. The leverage point is to anchor the goal or examine why the goal is drifted [61]. Another archetype is the limits to success archetype or when an initial growth is constrained by a limiting condition. The leverage point is to identify and remove the limiting factor [62]. In this research, system archetypes were identified by investigating the final CLD for specific system behaviour that fits those of system archetypes. Based on the identified archetype and leverage point, recommendations to university policies to improve $\mathrm{PhD}-\mathrm{WB}$ were presented.

\section{Results and Discussion}

\subsection{Variables Related to $P h D-W B$}

As a result of the MICMAC analysis, the 14 most important variables were categorised into the nine groups namely (1) environmental, (2) determinant, (3) rely, (4) stake, (5) target, (6) depending, (7) autonomous, (8) secondary, and (9) disconnect groups. However, none of the variables falls into disconnecting, depending and stake groups (see Figure 4). The outcomes can help better distinguish the variables based on their role and level of influence in the system. For instance, family/friends/peer support is categorised as an environmental variable that is independent from the other variables, indicating that $\mathrm{PhD}$ students constantly need moral support regardless of how successful they are in research. The determinant variable, supervisor's support, was important to PhD students' ability to cope with stress even if the students are confident about their research. Another example is the target variable, self-efficacy, or the $\mathrm{PhD}$ students' belief about their capability to execute necessary tasks to complete their $\mathrm{PhD}$. When students trust in their skills, they will be less stressed, more productive, and efficient. MICMAC also indicated that the extra non-curricular commitments and offered facilities by University variables have a negligible influence on system behaviour comparative to other variables but are essential to $\mathrm{PhD}$ students' stress levels. No dependent variables were identified by MICMAC analysis, meaning that all 14 variables can cause and resulted in $\mathrm{PhD}-\mathrm{WB}$ at the same time as a result of feedback loops.

Figure 5 illustrates that each stakeholder group ranked the influence of 14 most important variables on PhD-WB differently. For example, PhD students identified that stress level erodes their well-being the most, while PhD supervisors ranked stress level less important to $\mathrm{PhD}-\mathrm{WB}$ and prioritise $\mathrm{PhD}$ project moving forward. Supervisors also believe that consensus among supervisors is more important to PhD-WB than students do. In other words, supervisors assume that the need to 'please' more than one supervisor creates additional pressure on $\mathrm{PhD}$ students to a moderate different opinion. Moreover, the consensus among supervisors indicates the quality of their relationships, meaning that having a diverse supervision team is more of a cornerstone for supervisors than for students. This research demonstrates that by using MICMAC, the different perceptions among stakeholders could be revealed. Such understanding may assist a modeller in understanding stakeholders and which variables to focus on while conceptualising the system $[51,52]$. 


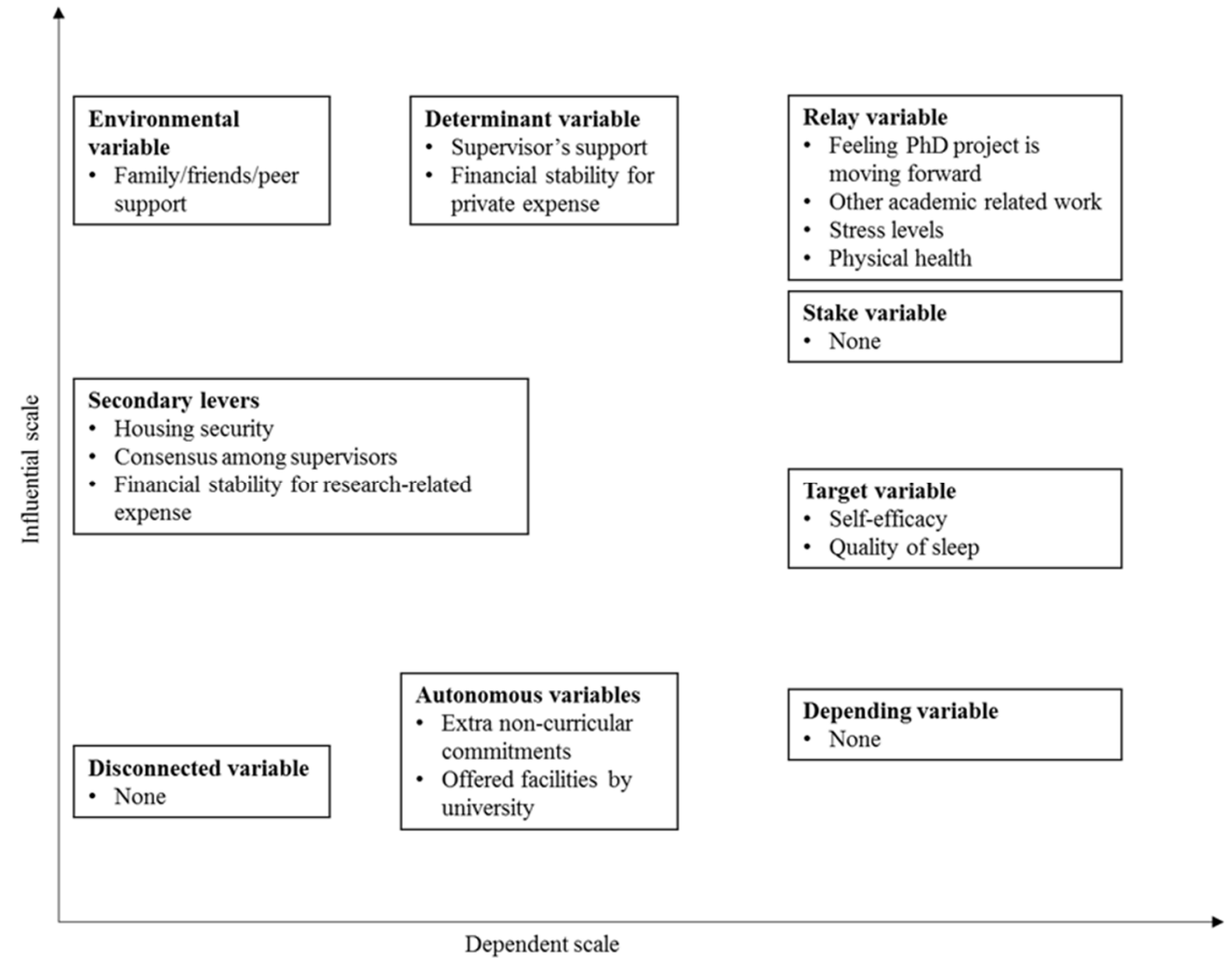

Figure 4. PhD-WB variable classification based on levels of direct influence calculated with MICMAC analysis.

Influence Ranking by Stakeholders

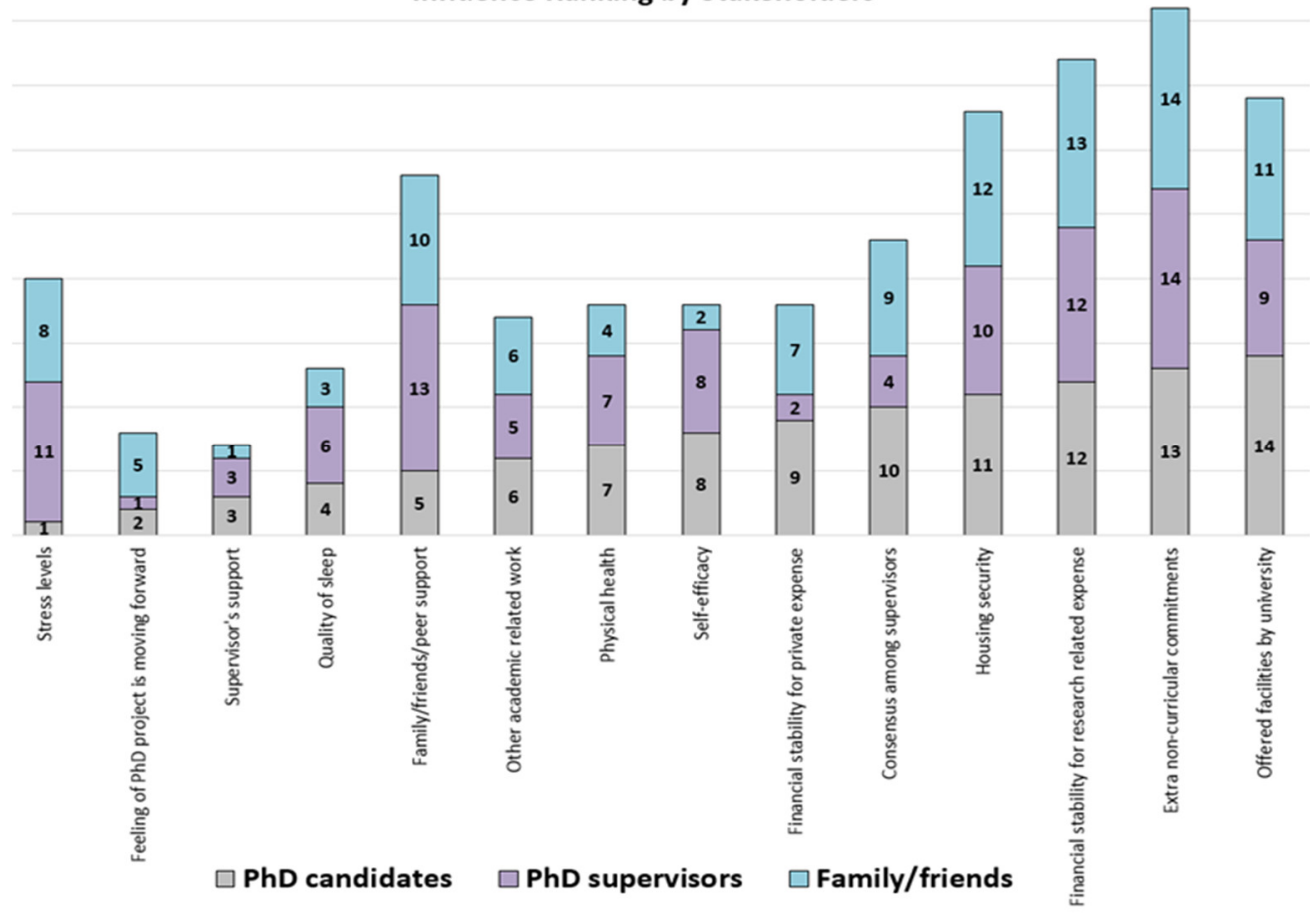

Figure 5. Influence PhD students' well-being variable ranking by $\mathrm{PhD}$ students, $\mathrm{PhD}$ supervisors, PhD families/friends. 


\subsection{The Complex System of PhD-WB}

During the interviews and focus group, each stakeholder group had their own opinions of what enables PhD students to have positive mental well-being. For example, $\mathrm{PhD}$ students identified well-being enabler as 'academic future job security' and 'number of publications' because they were concerned about their academic performance and future career. The PhD supervisors were interested in what contributes to the progress of a $\mathrm{PhD}$ project, while PhD students' family and friends were highlighting family/friend support and family commitment.

Following the interviews and focus group, stakeholders maintain all 14 MICMAC variables, and added 16 new variables, bringing to the total of 30 variables in the final CLD (Figure 6). From the final CLD, all variables related to Fredrickson [16]'s, Demerouti, Bakker, Nachreiner and Schaufeli [30]'s, and Liden and Maslyn [31]'s theories remain, while some variables related to the PhD well-being in an Australian university context were added. This confirms the importance of PhD students' emotions, available resources for $\mathrm{PhD}$ project, and supervisor-student relationships for the PhD students to experience positive mental well-being. Some of these 30 variables coincide with those influencing the well-being of academic staff, such as good role model and balancing work/life [63,64].

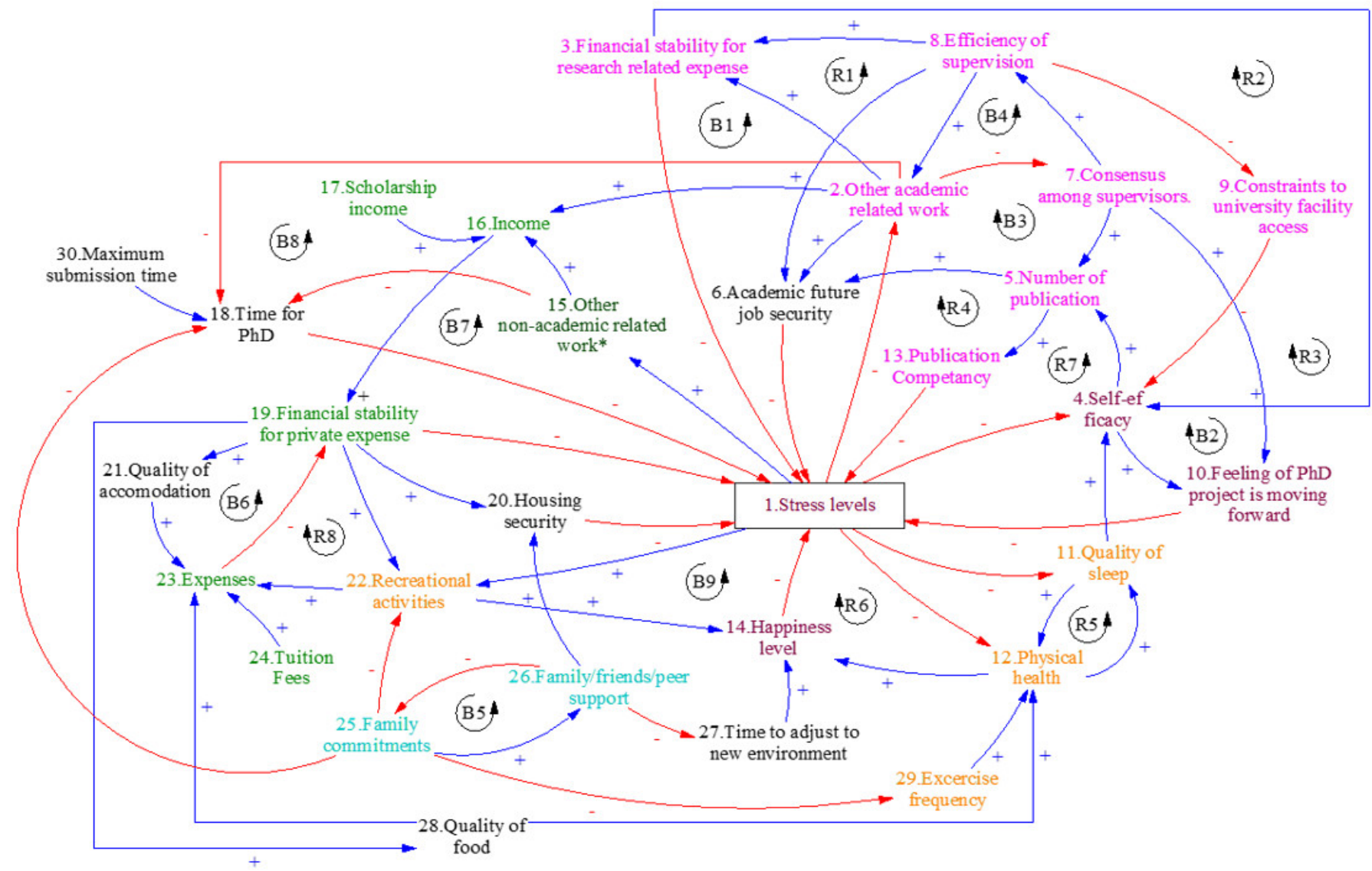

\begin{tabular}{|l|l|l|l|l|l|}
\hline University related & Mental & Finance & Physical & Family/friends & Others \\
\hline
\end{tabular}

Figure 6. The final CLD for PhD students' well-being in the context of Griffith University, Australia.

The final CLD (Figure 6) illustrates the complex interactions among six themes, including university, mental health, finance, physical, family/friends, and others, and were coloured differently. Seventeen feedback loops were identified, including nine balancing and eight reinforcing loops (Table 2). 
Table 2. List of feedback loops shown in Figure 6.

\begin{tabular}{cc}
\hline Loop & Variables \\
\hline R1 & $3 \rightarrow 1 \rightarrow 2 \rightarrow 7 \rightarrow 8$ \\
R2 & $3 \rightarrow 4 \rightarrow 10 \rightarrow 1 \rightarrow 2$ \\
R3 & $3 \rightarrow 4 \rightarrow 5 \rightarrow 6 \rightarrow 1 \rightarrow 2$ \\
R4 & $3 \rightarrow 4 \rightarrow 5 \rightarrow 13 \rightarrow 1 \rightarrow 2$ \\
R5 & $11 \rightarrow 12$ \\
R6 & $1 \rightarrow 12 \rightarrow 14$ \\
R7 & $1 \rightarrow 4 \rightarrow 5 \rightarrow 6$ \\
R8 & $22 \rightarrow 23 \rightarrow 19$ \\
B1 & $3 \rightarrow 1 \rightarrow 2$ \\
B2 & $3 \rightarrow 4 \rightarrow 10 \rightarrow 1 \rightarrow 2 \rightarrow 7 \rightarrow 8$ \\
B3 & $1 \rightarrow 2 \rightarrow 7 \rightarrow 8 \rightarrow 3 \rightarrow 4 \rightarrow 5 \rightarrow 6$ \\
B4 & $3 \rightarrow 4 \rightarrow 5 \rightarrow 13 \rightarrow 1 \rightarrow 2 \rightarrow 7 \rightarrow 8$ \\
B5 & $25 \rightarrow 26$ \\
B6 & $19 \rightarrow 21 \rightarrow 23$ \\
B7 & $15 \rightarrow 18 \rightarrow 1$ \\
B8 & $1 \rightarrow 2 \rightarrow 18$ \\
B9 & $1 \rightarrow 22 \rightarrow 14$ \\
\hline
\end{tabular}

For example, loop B1 from Table 2 indicates PhD-WB is enhanced if financial support for research is available and a future academic career is secured. The eight reinforcing loops, for example, erode PhD-WB through extra academic works, the feeling $\mathrm{PhD}$ is not moving forward (R1, R2), and the publish-or-perish policy (R3).

\subsection{System Archetypes}

The first archetype identified in the CLD is the limit to success archetype (Figure 7). This archetype represents an occasion where a short-term success is offset by a dynamic action of a balancing loop [65]. In the case of PhD-WB at GU, when PhD students are unable to publish a journal article, they have lower self-efficacy and become stressed (reinforcing effect). Over time, stressed PhD students will disengage from other academicrelated works, focus on their PhD research and become less stressed (balancing effect). However, PhD students stress will increase once more because of: (1) a maximum $\mathrm{PhD}$ thesis submission time; and (2) engaging less in other academic-related work diminishes their future academic job security.

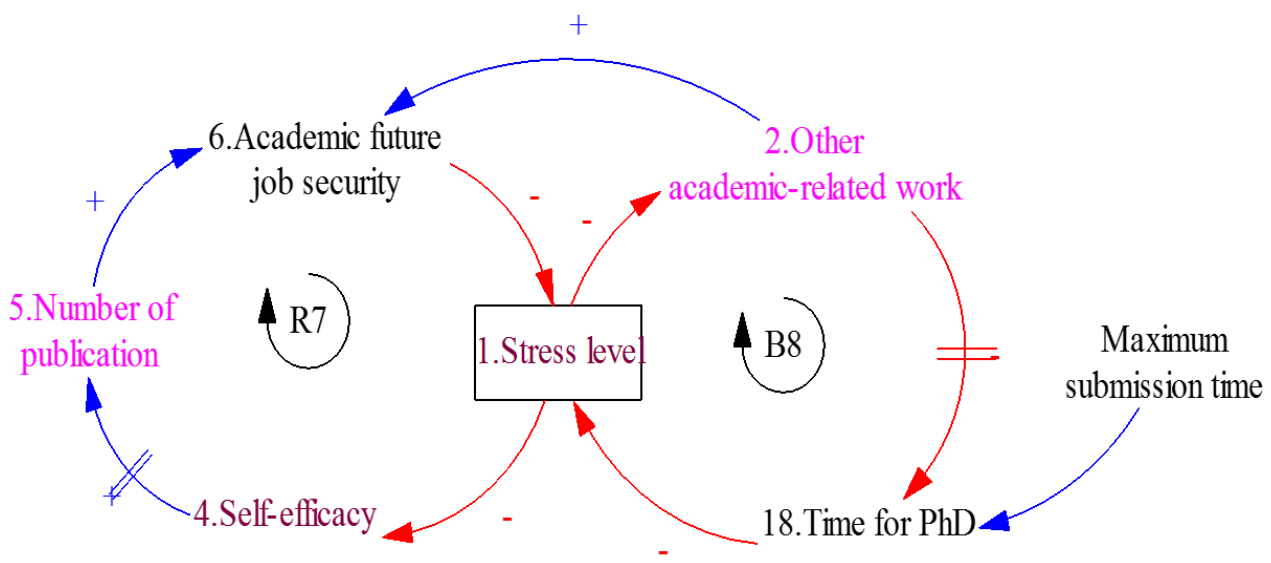

\begin{tabular}{|c|c|c|}
\hline University related & Mental & Others \\
\hline
\end{tabular}

Figure 7. Structure of limit to success archetype for an academic-related stressor to PhD students. 
The leverage point to limits to success is to remove the constraints, such as thesis submission milestones which encourages PhD students' progress but causes extra pressure. This research doesn't suggest the elimination of the submission due date, but rather to set the date based on students' circumstances. For example, PhD students who spend their first year refining their research projects should have their submission date extended, particularly those from the social science and humanities schools [66]. Similarly, students engaging in other academic-related works such as teaching should also have their submission date extended. Such engagements help to promote the transferable skills of a PhD student other than a narrow focus on research during the candidature. This research does not infer that extending a due date to PhD students with extra-curricular activities would eliminate their stress, as stress is reportedly associated with studying $[67,68]$. Rather, by increasing university's understanding and support through policy intervention, students with competing obligations may increase their retention and completion rates and promote student well-being $[69,70]$.

The limits to success archetype indicates the continuous tracking of information from available time resource [30] to PhD students' emotions [16]. Negative emotions then subsequently impact student performance, thus further increase the intensity of negative emotions. This feedback mechanism (see dotted line in Figure 1) is missing from the literature and yet significant in both theoretical and operational terms. Thus, this research made a theoretical contribution by adding the feedback arrow in Figure 1 whereby the PhD students' well-being can influence their emotions.

The second archetype found in the CLD is called fixes that fail (Figure 8). This archetype commonly occurs when the solution alleviates the problem in the short-term, but its side effects exacerbate the problem over the long run [60]. This archetype consists of a balancing loop to solve a problem by an immediate fix and a reinforcing loop to represent a delayed side effect. In this case the problem is negative emotions (i.e., stress) experiencing by PhD students. The common solution is to participate in recreational activities. Although, students can refresh and become untroubled over the short term through participating in recreational activities (balancing effect), it may lead to financial problems causing more stress over a long-term horizon (reinforcing effect).

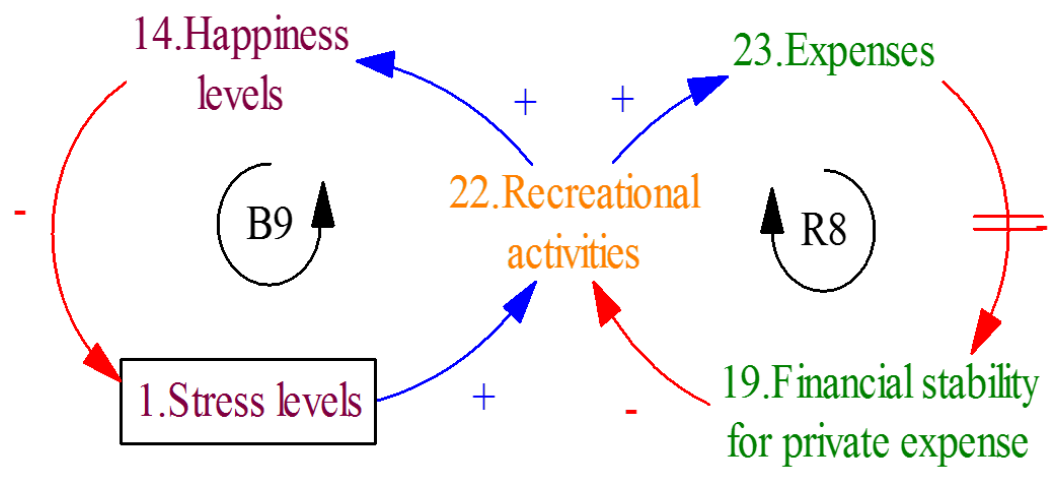

\begin{tabular}{|l|l|l|}
\hline Mental & Finance & Physical \\
\hline
\end{tabular}

Figure 8. Structure of fixes that fail archetype for recreational activities to relieve PhD student's stress.

The leverage point of the fixes that fail archetype is to focus on long-term strategies for PhD students' well-being. A quick fix should only be applied to 'buy time' when the fundamental solution is in progress [59]. The long-term behaviour of the fixes that fail archetype reveals that participating in a recreational activity to enhance well-being is not a fundamental solution to reduce PhD-related stress. This research does not argue the merit of resistance strategies to $\mathrm{PhD}-\mathrm{WB}$, such as positive thinking [20] and organising fitness groups [11]. However, the result of this study is in agreement with Golde [14] 
that restructuring doctoral education is a long-term solution to improve PhD-WB. Study results indicate that there is a need to change universities culture of untying PhD students' academic progress with the number of publications and conferences attendances. Instead, universities should place emphasis on building skills other than research such as creativity, critical thinking, and autonomous intellectual risk-taking [71] to give PhD students selfsatisfaction through improvement and transferable knowledge beyond academia. In the UK, the government has funded skill development programs among PhD students and post-doctoral researchers in STEM disciplines [72].

Similarly, PhD student's industry collaboration is embedded in Canada's Network Centre of Excellence program. The program led to a surprising increase of industrial internships from 17 in 2003 to 3200 in 2014-2015, indicating transferable skills to the industry [73]. In Australia, however, programs that develop transferable skills are not implanted in doctoral education, with no dedicated government fund or monitoring for career outcomes [73]. More needs to be done to connect PhD graduates with industry given that less than $50 \%$ of them are being employed within the university sector [74].

\section{Conclusions}

This research illustrates that PhD candidature is not an individual journey, nor that PhD students' well-being is solely subject to how ones perceive their surroundings. Rather, PhD-WB relies on factors including the university, the financial support, students' physical health, and their family/friends; many of which are beyond the students' control.

By developing a CLD and understanding system's behaviour through archetypes, this research reveals that the roles of variables are ambiguous and subject to system behaviours. Variables can act positively (i.e., as a driver) or negatively (i.e., as a barrier) at a certain time and under specific circumstances. For example, limiting other academic-related work, while leaving $\mathrm{PhD}$ students more time to focus on their studies could diminish the students future academic job security, opportunity to develop transferable skills to the industry and earning financial incomes during PhD candidature. In sum, students with poor wellbeing are negatively impacted twice. Once by lack of skill set to become a competitive job applicant, and the latter by lack of finance to engage in recreational activities. This research demonstrates the complexity of PhD-WB, which can uniquely be understood using a systems approach.

The research revealed how university support (or job resources to which Demerouti, Bakker, Nachreiner and Schaufeli [30] refers) could encourage positive emotions among PhD students' (or emotions to which Fredrickson [16] refers); and how their emotions can be improved based on the relationships among the supervisory team (or supervisor-student relationship to which Liden and Maslyn [31] refer). This finding highlighted that the three different theories of Fredrickson [16], Demerouti, Bakker, Nachreiner and Schaufeli [30], and Liden and Maslyn [31] are highly compatible and overlap. By relating these theories, the well-being as a complex system among PhD students was explained. Such theory integration can help future research to understand why a PhD student might experience well- or ill-being.

The authors acknowledge a multidisciplinary stakeholder team limits the risk of incoherence and builds a common knowledge of PhD-WB; a group can make a collective mistake. Future research is recommended to develop a quantitative system dynamics model, guided by the CLD proposed in this research, which can be used for model testing, policy design and evaluation using quantitative methods [39]. A quantitative system dynamics model could become a platform for the universities to understand key variables impacting PhD students' well-being, and ultimately, to develop policies to reduce PhD student's attrition rates.

Author Contributions: Conceptualization, N.D., E.S., M.H., and S.M.; methodology, N.D., E.S., S.M., M.H., and O.S.; software, N.D., and E.S.; validation, M.H., and S.M.; investigation, N.D., E.S., and S.M.; resources, data curation, E.S., and S.M.; writing—original draft preparation, N.D., E.S., M.H., 
and S.M.; writing—review and editing, O.S.; visualization, E.S. and M.H.; supervision, O.S.; All authors have read and agreed to the published version of the manuscript.

Funding: This research did not receive any specific grant from funding agencies in the public, commercial, or not-for-profit sectors.

Institutional Review Board Statement: The study was conducted according with the National Statement on Ethical Conduct in Human Research (2007) and was approved by the Research Ethics of Griffith University (Ethics reference number 2017/974).

Informed Consent Statement: Informed consent was obtained from all subjects involved in the study.

Data Availability Statement: Not applicable.

Acknowledgments: The authors would like to thank all the research participants for their time and contribution.

Conflicts of Interest: No potential conflicts of interest were reported by the authors.

\section{Appendix A}

Table A1. MICMAC list of 14 variables related to PhD students' well-being at Griffith University, Australia context.

\begin{tabular}{|c|c|c|c|}
\hline No. & Variable & Description & Source \\
\hline 1 & Quality of sleep & $\begin{array}{l}\text { Quality of sleep has a negative correlation with stress. It has a moderating } \\
\text { effect between psychological/academic stress and physical stress. Quality of } \\
\text { sleep is also related to academic performance. Quality of sleep was found to } \\
\text { deteriorate under stressful conditions, particularly among females and those } \\
\text { who are prone to stress. }\end{array}$ & {$[75,76]$} \\
\hline 2 & $\begin{array}{l}\text { Consensus among } \\
\text { supervisors }\end{array}$ & $\begin{array}{l}\text { Most of the PhD projects involve more than one supervisor. The consensus } \\
\text { among supervisors can ease pressure on PhD students to moderate different } \\
\text { opinion. It also provides PhD students a clearer direction. The consensus } \\
\text { among supervisors indicates the quality of their relationships. }\end{array}$ & As per experts \\
\hline 3 & $\begin{array}{l}\text { Other } \\
\text { academic-related work }\end{array}$ & $\begin{array}{l}\text { Other academic-related work refers to a research assistant and } \\
\text { teaching-related tasks. Although these may advance PhD student's career, it } \\
\text { was not designed to help ensure high quality learning for the students, but } \\
\text { rather to serve the faculty's need. }\end{array}$ & [19] \\
\hline 4 & $\begin{array}{l}\text { The feeling of } \mathrm{PhD} \\
\text { project is moving } \\
\text { forward }\end{array}$ & $\begin{array}{l}\text { The feelings of PhD students towards their projects that: } \\
\text { (1) it makes sense to them; } \\
\text { (2) it is progressing. }\end{array}$ & [77] \\
\hline 5 & $\begin{array}{l}\text { Family/friends/peer } \\
\text { support }\end{array}$ & $\begin{array}{l}\text { Emotional support from family, friends, and other PhD students plays a } \\
\text { positive role during the candidature. However, it does not prevent them } \\
\text { from dropping off because family/friends/peers do not contribute to the } \\
\text { PhD project progress. }\end{array}$ & [77] \\
\hline 6 & Supervisor's support & $\begin{array}{l}\text { PhD student's supervisors play a crucial role in the PhD project progress, } \\
\text { and hence, whether the student may drop out of the program or not. }\end{array}$ & {$[77,78]$} \\
\hline 7 & Housing security & $\begin{array}{l}\text { Stability of PhD student's housing arrangement including: } \\
\text { (1) tenure (or the conditions under which land or buildings are held or } \\
\text { occupied); } \\
\text { (2) relationship with other housing occupants; } \\
\text { (3) the suitability of housing. }\end{array}$ & As per experts \\
\hline 8 & Physical health & The physical condition of an individual, absence of ill health & [78] \\
\hline 9 & Stress levels & $\begin{array}{l}\text { Anxiety, depression, burnout, emotional exhaustion. Feeling of strain and } \\
\text { pressure. Usually caused by imbalance between the individual and one's } \\
\text { environment. }\end{array}$ & [78] \\
\hline 10 & Self-efficacy & $\begin{array}{l}\text { PhD student's belief in his or her capacity to execute tasks necessary to } \\
\text { complete the degree. }\end{array}$ & $\begin{array}{l}\text { As per experts, } \\
{[79]}\end{array}$ \\
\hline
\end{tabular}


Table A1. Cont.

\begin{tabular}{cclc}
\hline No. & Variable & \multicolumn{1}{c}{ Description } & Source \\
\hline 11 & $\begin{array}{c}\text { Financial stability for } \\
\text { private expense }\end{array}$ & $\begin{array}{l}\text { PhD students have financial resources to cover personal expenses. This } \\
\text { could be through the PhD students themselves, partners, family, etc. }\end{array}$ & As per experts \\
\hline 12 & $\begin{array}{c}\text { Financial stability for } \\
\text { research-related } \\
\text { expense }\end{array}$ & $\begin{array}{l}\text { PhD students receive financial assistance such as grants and scholarships to } \\
\text { cover tuition fees, conference fees, and so on. }\end{array}$ As per experts \\
\hline 13 & $\begin{array}{c}\text { Offered facilities by } \\
\text { university }\end{array}$ & $\begin{array}{l}\text { Access to research facilities such as an own desk, a personal computer, free } \\
\text { access to a telephone, free printing, as well as lab access with sufficient } \\
\text { equipment and materials and, access to required data and information. }\end{array}$ \\
\hline 14 & $\begin{array}{c}\text { Extra non-curricular } \\
\text { commitments }\end{array}$ & $\begin{array}{l}\text { Extra activities such as family commitments, caring roles, and } \\
\text { unrelated-academic work can add workload to PhD students. }\end{array}$ \\
\hline
\end{tabular}

\section{References}

1. Langford, P.H. Benchmarking work practices and outcomes in australian universities using an employee survey. J. High. Educ. Policy Manag. 2010, 32, 41-53. [CrossRef]

2. Anttila, H.; Lindblom-Ylänne, S.; Lonka, K.; Pyhältö, K. The added value of a phd in medicine-phd students' perceptions of acquired competences. Int. J. High. Educ. 2015, 4, 172-180. [CrossRef]

3. Cornér, S.; Löfström, E.; Pyhältö, K. The relationship between doctoral students' perceptions of supervision and burnout. Int. J. Dr. Stud. 2017, 12, 91-106. [CrossRef]

4. Jiranek, V. Potential predictors of timely completion among dissertation research students at an australian faculty of sciences. Int. J. Dr. Stud. 2010, 5, 1-13. [CrossRef]

5. World Health Organization. Mental Health: A State of Well-Being. Available online: https://www.who.int/features/factfiles/ mental_health/en/ (accessed on 1 October 2020).

6. Laudel, G.; Gläser, J. From apprentice to colleague: The metamorphosis of early career researchers. High. Educ. 2008, 55, 387-406. [CrossRef]

7. Tucker, F.; Horton, J. "The show must go on!" fieldwork, mental health and wellbeing in geography, earth and environmental sciences. Area 2019, 51, 84-93. [CrossRef]

8. Hunter, K.H.; Devine, K. Doctoral students' emotional exhaustion and intentions to leave academia. Int. J. Dr. Stud. 2016, 11, 35-61.

9. Herrmann, K.J.; Wichmann-Hansen, G. Validation of the quality in phd processes questionnaire. Stud. Grad. Postdr. Educ. 2017, 8, 189-204. [CrossRef]

10. Stubb, J.; Pyhältö, K.; Lonka, K. Balancing between inspiration and exhaustion: Phd students' experienced socio-psychological well-being. Stud. Contin. Educ. 2011, 33, 33-50. [CrossRef]

11. Haynes, C.; Bulosan, M.; Citty, J.; Grant-Harris, M.; Hudson, J.C.; Koro-Ljungberg, M. My world is not my doctoral program ... or is it?: Female students' perceptions of well-being. Int. J. Dr. Stud. 2012, 7, 1-17. [CrossRef]

12. Martinez, E.; Ordu, C.; Della Sala, M.R.; McFarlane, A. Striving to obtain a school-work-life balance: The full-time doctoral student. Int. J. Dr. Stud. 2013, 8, 39-59. [CrossRef]

13. Pychyl, T.A.; Little, B.R. Dimensional specificity in the prediction of subjective well-being: Personal projects in pursuit of the phd. Soc. Indic. Res. 1998, 45, 423-473. [CrossRef]

14. Golde, C.M. The role of the department and discipline in doctoral student attrition: Lessons from four departments. J. High. Educ. 2005, 76, 669-700. [CrossRef]

15. Schmidt, M.; Hansson, E. Doctoral students' well-being: A literature review. Int. J. Qual. Stud. Health Well-Being 2018, $13,1508171$. [CrossRef] [PubMed]

16. Fredrickson, B.L. The role of positive emotions in positive psychology. The broaden-and-build theory of positive emotions. Am. Psychol. 2001, 56, 218-226.

17. Ison, R. Applying systems thinking to higher education. Syst. Res. Behav. Sci. 1999, 16, 107-112. [CrossRef]

18. Group of Eight House. The Changing Phd: Discussion Paper. Available online: https://go8.edu.au/files/docs/the-changingphd_final.pdf (accessed on 1 October 2020).

19. Austin, A.E. Preparing the next generation of faculty. J. High. Educ. 2002, 73, 94-122. [CrossRef]

20. Shavers, M.C.; Moore, J.L.I. Black female voices: Self-presentation strategies in doctoral programs at predominately white institutions. J. Coll. Stud. Dev. 2014, 55, 391-407. [CrossRef]

21. Miller, A.N.; Taylor, S.G.; Bedeian, A.G. Publish or perish: Academic life as management faculty live it. Career Dev. Int. 2011, 16, 422-445. [CrossRef]

22. Caesens, G.; Stinglhamber, F.; Luypaert, G. The impact of work engagement and workaholism on well-being: The role of work-related social support. Career Dev. Int. 2014, 19, 813-835. [CrossRef] 
23. Schmidt, M.; Umans, T. Experiences of well-being among female doctoral students in sweden. Int. J. Qual. Stud. Health Well-Being 2014, 9, 23059. [CrossRef]

24. Moberg, D.O. The development of social indicators for quality of life research. Sociol. Anal. 1979, 40, 11-26. [CrossRef]

25. Stubb, J.; Pyhältö, K.; Lonka, K. The experienced meaning of working with a phd thesis. Scand. J. Educ. Res. 2012, 56, 439-456. [CrossRef]

26. Hudson, S.A.; O’Regan, J. Stress and the graduate psychology student. J. Clin. Psychol. 1994, 50, 973-977. [CrossRef]

27. Chen, X.; Fan, X.; Cheung, H.Y.; Wu, J. The subjective well-being of academically gifted students in the chinese cultural context. Sch. Psychol. Int. 2018, 39, 291-311. [CrossRef]

28. Lutovac, S.; Kaasila, R.; Komulainen, J.; Maikkola, M. University lecturers' emotional responses to and coping with student feedback: A finnish case study. Eur. J. Psychol. Educ. 2017, 32, 235-250. [CrossRef]

29. Midgley, G. Theoretical pluralism in systemic action research. Syst. Pract. Action Res. 2011, 24, 1-15. [CrossRef]

30. Demerouti, E.; Bakker, A.B.; Nachreiner, F.; Schaufeli, W.B. The job demands-resources model of burnout. J. Appl. Psychol. 2001, 86, 499-512. [CrossRef] [PubMed]

31. Liden, R.C.; Maslyn, J.M. Multidimensionality of leader-member exchange: An empirical assessment through scale development. J. Manag. 1998, 24, 43-72. [CrossRef]

32. Clements, A.J.; Kamau, C. Understanding students' motivation towards proactive career behaviours through goal-setting theory and the job demands-resources model. Stud. High. Educ. 2018, 43, 2279-2293. [CrossRef]

33. Mudrak, J.; Zabrodska, K.; Kveton, P.; Jelinek, M.; Blatny, M.; Solcova, I.; Machovcova, K. Occupational well-being among university faculty: A job demands-resources model. Res. High. Educ. 2018, 59, 325-348. [CrossRef]

34. Hockey, J. Getting too close: A problem and possible solution in social science phd supervision. Br. J. Guid. Couns. 1995, 23, 199-210. [CrossRef]

35. Deuchar, R. Facilitator, director or critical friend?: Contradiction and congruence in doctoral supervision styles. Teach. High. Educ. 2008, 13, 489-500. [CrossRef]

36. Lee, A.; McKenzie, J. Evaluating doctoral supervision: Tensions in eliciting students' perspectives. Innov. Educ. Teach. Int. 2011, 48, 69-78. [CrossRef]

37. Mosley, C.; Broyles, T.; Kaufman, E. Leader-member exchange, cognitive style, and student achievement. J. Leadersh. Educ. 2014, 13, 50-69. [CrossRef]

38. Jacques, P.H.; Garger, J.; Thomas, M.; Vracheva, V. Effects of early leader-member exchange perceptions on academic outcomes. Learn. Environ. Res. 2012, 15, 1-15. [CrossRef]

39. Sterman, J. Business Dynamics: Systems Thinking and Modeling for a Complex World; McGraw-Hill Education: Boston, MA, USA, 2000 .

40. Universities. Universities Australia. Available online: https://www.universitiesaustralia.edu.au/ (accessed on 1 October 2020).

41. Griffith University. Facilities Support. Available online: https://intranet.secure.griffith.edu.au/research/griffith-graduateresearch-school/resources / facilities-support (accessed on 1 October 2020).

42. Australian Government Department of Education. Research Training Program. Available online: https://www.education.gov. au/research-training-program (accessed on 1 October 2020).

43. Melbourne Institute of Applied Economic and Social Research. Poverty Lines: Australia; Melbourne Institute of Applied Economic and Social Research: Melbourne, VIC, Australia, 2017.

44. Australian Bureau of Statistics. Average Weekly Earnings, Australia. Available online: https://www.abs.gov.au/ausstats/abs@ .nsf/mf/6302.0?opendocument\&ref=HPKI (accessed on 1 October 2020).

45. Potter, B.; Tillett, A. Australian Households Pay Highest Power Prices in World. Available online: https://www.afr.com/politics/ australian-households-pay-highest-power-prices-in-world-20170804-gxp58a (accessed on 1 October 2020).

46. Reynolds, M.; Holwell, S. Introducing Systems Approaches: Systems Approaches to Managing Change: A Practical Guide; Springer: London, UK, 2010.

47. Gregory, W.J. Discordant pluralism: A new strategy for critical systems thinking. Syst. Pract. 1996, 9, 605-625. [CrossRef]

48. Midgley, G. Systemic Intervention: Philosophy, Methodology, and Practice (Contemporary Systems Thinking); Springer Science \& Business Media: New York, NY, USA, 2001.

49. Arcade, J.; Godet, M.; Meunier, F.; Roubelat, F. Structural Analysis with the Micmac Method E Actor's Strategy with Mactor Method; The Millennium Project: Washington, DC, USA, 1999.

50. Onyango, E.A.; Sahin, O.; Chu, C.; Mackey, B. An Integrated Modelling Approach to Climate Change and Malaria Vulnerability Assessments. In Proceedings of the 8th International Congress on Environmental Modelling and Software, Toulouse, France, 10-14 July 2016.

51. Suprun, E.; Sahin, O.; Stewart, R.; Panuwatwanich, K. Model of the russian federation construction innovation system: An integrated participatory systems approach. Systems 2016, 4, 29. [CrossRef]

52. Torres, N.; Olaya, C. Tackling the Mess: Systems Conceptualization through Cross-Impact Analysis. In Proceedings of the 28th International Conference of the System Dynamics Society, Seoul, Korea, 25-29 July 2010.

53. Müller, M.O.; Groesser, S.N.; Ulli-Beer, S. How do we know who to include in collaborative research? Toward a method for the identification of experts. Eur. J. Oper. Res. 2012, 216, 495-502. [CrossRef]

54. Dhirasasna, N.; Sahin, O. A multi-methodology approach to creating a causal loop diagram. Systems 2019, 7, 42. [CrossRef] 
55. Suprun, E.; Sahin, O.; Stewart, R.; Panuwatwanich, K.; Shcherbachenko, Y. An integrated participatory systems modelling approach: Application to construction innovation. Systems 2018, 6, 33. [CrossRef]

56. Chevalier, J.; Buckles, D. Sas ${ }^{2}$ : A Guide to Collaborative Inquiry and Social Engagement; SAGE Publications India Pvt Ltd.: New Delhi, India, 2008.

57. MICMAC. Micmac: Methods of Prospectives (Computer Software). Available online: http:/ / en.laprospective.fr/methods-ofprospective/softwares/59-micmac.html (accessed on 1 October 2020).

58. Martinez-Moyano, I.J.; Richardson, G.P. Best practices in system dynamics modeling. Syst. Dyn. Rev. 2013, 29, 102-123. [CrossRef]

59. Senge, P.M. The Fifth Discipline: The Art and Practice of the Learning Organization, 2nd ed.; Random House Business: New York, NY, USA, 2006.

60. Braun, W. The System Archetypes. Available online: http://www.uni-klu.ac.at/ \{\}gossimit/pap/sd/wb_sysarch.pdf (accessed on 1 October 2020).

61. Salim, H.K.; Stewart, R.A.; Sahin, O.; Dudley, M. Systems approach to end-of-life management of residential photovoltaic panels and battery energy storage system in australia. Renew. Sustain. Energy Rev. 2020, 134, 110176. [CrossRef]

62. Sahin, O.; Salim, H.; Suprun, E.; Richards, R.; MacAskill, S.; Heilgeist, S.; Rutherford, S.; Stewart, R.A.; Beal, C.D. Developing a preliminary causal loop diagram for understanding the wicked complexity of the covid-19 pandemic. Systems $2020,8,20$. [CrossRef]

63. Boyd, P.; Smith, C. The contemporary academic: Orientation towards research work and researcher identity of higher education lecturers in the health professions. Stud. High. Educ. 2016, 41, 678-695. [CrossRef]

64. Smith, C.; Boyd, P. Becoming an academic: The reconstruction of identity by recently appointed lecturers in nursing, midwifery and the allied health professions. Innov. Educ. Teach. Int. 2012, 49, 63-72. [CrossRef]

65. Maani, K.E.; Cavana, R.Y. Systems Thinking, System Dynamics: Managing Change and Complexity; Prentice Hall: Auckland, New Zealand, 2007.

66. Humphrey, R.; Marshall, N.; Leonardo, L. The impact of research training and research codes of practice on submission of doctoral degrees: An exploratory cohort study. High. Educ. Q. 2012, 66, 47-64. [CrossRef]

67. Geven, K.; Skopek, J.; Triventi, M. How to increase phd completion rates? An impact evaluation of two reforms in a selective graduate school, 1976-2012. Res. High. Educ. 2018, 59, 529-552. [CrossRef]

68. Ladner, J.; Mihailescu, S.; Kern, L.; Romo, L.; Tavolacci, M. Burn out in university students: Time now for implementing new public health approaches: Joel ladner. Eur. J. Public Health 2016, 26, ckw172.042. [CrossRef]

69. Schroeder, M.; Makarenko, E.; Warren, K. Introducing a late bank in online graduate courses: The response of students. Can. J. Scholarsh. Teach. Learn. 2019, 10. [CrossRef]

70. Smith, S. Student-Mothers in Community College: A Populous and Overlooked Demographic in Critical Need for Support and Understanding; Northern Kentucky University: Ann Arbor, MI, USA, 2019.

71. Reisz, M. The Australian Approach to Improving Phd Completion Rates. Available online: https://www.insidehighered.com/ news / 2017/04/13/improve-phd-completion-rates-australian-universities-use-metrics-their-supervisors (accessed on 1 October 2020).

72. Science and Technology Facilities Council. Transferable Skills Development. Available online: https://stfc.ukri.org/skills/ impact-of-our-skills/postgraduate-training-and-skills/transferable-skills-development/ (accessed on 1 October 2020).

73. Marsh, H.; Western, M. How to Improve Research Training in Australia-Give Industry Placements to Phd Students. Available online: https:/ / theconversation.com/how-to-improve-research-training-in-australia-give-industry-placements-to-phdstudents-57972 (accessed on 1 October 2020).

74. McGagh, J.; Marsh, H.; Western, M.; Thomas, P.; Hastings, A.; Mihailova, M.; Wenham, M. Review of Australia's Research Training System; Report for the Australian Council of Learned Academies; Australian Council of Learned Academies: Melbourne, Australia, 2016.

75. Abdulghani, H.M.; Alrowais, N.A.; Bin-Saad, N.S.; Al-Subaie, N.M.; Haji, A.M.A.; Alhaqwi, A.I. Sleep disorder among medical students: Relationship to their academic performance. Med. Teach. 2012, 34, S37-S41. [CrossRef]

76. Lund, H.G.; Reider, B.D.; Whiting, A.B.; Prichard, J.R. Sleep patterns and predictors of disturbed sleep in a large population of college students. J. Adolesc. Health 2010, 46, 124-132. [CrossRef] [PubMed]

77. Devos, C.; Boudrenghien, G.; Van der Linden, N.; Azzi, A.; Frenay, M.; Galand, B.; Klein, O. Doctoral students' experiences leading to completion or attrition: A matter of sense, progress and distress. Eur. J. Psychol. Educ. 2017, 32, 61-77. [CrossRef]

78. Levecque, K.; Anseel, F.; De Beuckelaer, A.; Van der Heyden, J.; Gisle, L. Work organization and mental health problems in phd students. Res. Policy 2017, 46, 868-879. [CrossRef]

79. American Psychological Association. Teaching Tip Sheet: Self-Efficacy. Available online: https://www.apa.org/pi/aids/ resources/education/self-efficacy (accessed on 1 October 2020).

80. Waaijer, C.J.F.; Sonneveld, H.; Buitendijk, S.E.; van Bochove, C.A.; van der Weijden, I.C.M. The role of gender in the employment, career perception and research performance of recent phd graduates from dutch universities. PLoS ONE 2016, 11, e0164784. [CrossRef] [PubMed] 